ISSN 2179-6750

\title{
Práticas Integrativas e Complementares como ética da sensibilidade no cuidado humano
}

Traditional and Complementary Medicine such as the ethics of sensibility in human care Medicina Tradicional y Complementaria como la ética de la sensibilidad en el cuidado humano

\section{Alexandre Franca Barreto ${ }^{1}$}

\begin{abstract}
Resumo
Este artigo tem por objetivo refletir sobre a ética no cuidado das Práticas Integrativas e Complementares em Saúde (PICS). Nossa opção é afirmar uma ética da sensibilidade que atravessa o campo das PICS e que permite sua existência e ascensão na contemporaneidade à revelia da doxa dominante na saúde protagonizada pela racionalidade biomédica. Entretanto, as fronteiras não são tão rígidas na vida prática, o lugar de cuidador e de quem recebe o cuidado é ambivalente, ele se dá na experiência que atravessa as margens de diversas racionalidades e práticas de cuidado. Adotamos o testemunho como método para aprofundar este lugar híbrido da existência humana na saúde. Um dos testemunhos coloca como marcadores desta ética da sensibilidade o vínculo seguro, o trabalho de si e a experiência encarnada de cuidado. No segundo testemunho vemos a importância da transmissão desta ética da sensibilidade pela formação humana do profissional da saúde. A conclusão aponta que a ética da sensibilidade permeia o campo da PICS através do cuidado humanizado e dos recursos objetivos em seus processos de formação terapêutica que focalizam em dimensões sensíveis e profundas do humano. Entretanto, diante de um processo de institucionalização e possíveis capturas que transformem as PICS em mais um produto no mercado da saúde/doença, a ética da sensibilidade deve se atualizar a cada novo vínculo de cuidado, é a sustentação cotidiana da sensibilidade em cada nova relação e ato que poderá suportar esta dimensão ética no interior deste campo.
\end{abstract}

Descritores: Assistência Integral à Saúde; Humanização da Assistência; Ética.

\begin{abstract}
Este artículo tiene como objetivo reflexionar sobre la ética en el cuidado de la medicina tradicional y complementaria (MTC). Nuestra elección es afirmar una ética de la sensibilidad que atraviesa el campo de la MTC, lo que permite su existencia y su aumento en los tiempos contemporáneos, incluso con el campo de la salud dominado por la racionalidad biomédica. Sin embargo, los límites de estos campos no son tan rígidas en la vida práctica, el lugar del cuidador y de la persona que recibe el cuidado es ambivalente, que ocurre en la experiencia que cruza los márgenes de diversas racionalidades y prácticas de atención. Adoptamos el testimonio como un método para profundizar en este lugar híbrido de la existencia humana en la salud. Uno de los testigos pone como marcadores de la sensibilidad ética o enlace seguro, trabajar sí mismos y la experiencia encarnada de la atención. En el segundo testigo que vemos la importancia de la transmisión de esta sensibilidad ética para la formación humana de los profesionales de la salud. La conclusión muestra que la ética de la sensibilidad impregna el campo de la MTC a través de recursos de cuidados humanizados y objetivos en sus procesos de formación terapéuticos que se centran en las dimensiones sensibles y profundas del ser humano. Sin embargo, antes de que un proceso de
\end{abstract}

${ }^{1}$ Doutor em Educação pela Universidade Federal de Pernambuco (UFPE). Mestre em Antropologia pela Universidade Federal de Pernambuco (UFPE). Bacharel em Psicologia pela Universidade Católica de Pernambuco, UNICAP. Av. José de Sá Maniçoba, s/n, Centro, Recife, PE, Brasil, CEP: 56304-917. E-mail: alexandre.barreto@univasf.edu.br 
ISSN 2179-6750

institucionalización y posibles capturas que transforman la MTC en otro producto en el mercado de la salud / enfermedad, la ética de la sensibilidad debe ser actualizada en cada nueva relación de cuidado, es el suporte diario de la sensibilidad en cada nueva relación y acto que puede asegurar esta dimensión ética dentro de este campo.

Key-words: Comprehensive Health Care; Humanization of Assistance; Ethics.

\section{Resumen}

Este artículo tiene como objetivo reflexionar sobre la ética en el cuidado de la medicina tradicional y complementaria (MTC). Nuestra elección es afirmar una ética de la sensibilidad que atraviesa el campo de la MTC, lo que permite su existencia y su aumento en los tiempos contemporáneos, incluso con el campo de la salud dominado por la racionalidad biomédica. Sin embargo, los límites de estos campos no son tan rígidas en la vida práctica, el lugar del cuidador y de la persona que recibe el cuidado es ambivalente, que ocurre en la experiencia que cruza los márgenes de diversas racionalidades y prácticas de atención. Adoptamos el testimonio como un método para profundizar en este lugar híbrido de la existencia humana en la salud. Uno de los testigos pone como marcadores de la sensibilidad ética o enlace seguro, trabajar sí mismos y la experiencia encarnada de la atención. En el segundo testigo que vemos la importancia de la transmisión de esta sensibilidad ética para la formación humana de los profesionales de la salud. La conclusión muestra que la ética de la sensibilidad impregna el campo de la MTC a través de recursos de cuidados humanizados y objetivos en sus procesos de formación terapéuticos que se centran en las dimensiones sensibles y profundas del ser humano. Sin embargo, antes de que un proceso de institucionalización y posibles capturas que transforman la MTC en otro producto en el mercado de la salud / enfermedad, la ética de la sensibilidad debe ser actualizada en cada nueva relación de cuidado, es el suporte diario de la sensibilidad en cada nueva relación y acto que puede asegurar esta dimensión ética dentro de este campo.

Palabras-claves: Atención Integral de Salud; Humanización de la Atención; Ética.

\section{Introdução}

O termo Prática Integrativa e Complementar em Saúde (PICS) como sugere o Ministério da Saúde (MS) brasileiro ou Medicinas Tradicional e Complementar e Integrativa (MTCI) como propõe a Organização Mundial da Saúde (OMS), assim como vários outras expressões tais como "medicina holística" ou "saúde integrativa" que se veiculam nos meios de comunicação científicos ou em geral, situa um campo que traz a dimensão energética/vitalista como aspecto paradigmático e congrega uma pluralidade de abordagens e práticas ${ }^{1,2}$.

A dimensão energética - que na maioria das racionalidades médicas e práticas terapêuticas envolve uma anatomia sutil e singular do funcionamento do corpo humano em sua dinâmica do fluxo vital -, traz em seu bojo uma dimensão relacional/vincular mais ou menos implícita, que nos parece de relevância, para evidenciar uma potência do cuidado ofertado pelas PICS diante da lacuna deixada pela racionalidade biomédica.

Esta lacuna do sistema biomédico como sinaliza Madel $\mathrm{Luz}^{3}$ é um espaço no qual as novas 182 
ISSN 2179-6750

práticas terapêuticas ocupam um lugar importante na sociedade civil atual e com maior modéstia no âmbito da saúde pública no SUS (Sistema Único de Saúde). Elas sinalizam "sentidos, significados e valores diante do sofrimento, do adoecimento, bem como do tratamento e da cura de doenças, distintos dos dominantes" ${ }^{3}$ (p. 42).

Pelizzoli $^{4}$ pontua como as PICS emergem diante do estremo de uma tecnociência que alinhada a um modelo político-econômico, transforma "a prática de (re)conduzir saúde em contínuos momentos do histórico da vida" (p. 299) em um mercado de "saúde" (doença) alheio as necessidades de segurança alimentar, sanitária, ecológica e comunitária. As práticas corporais (incluso mentais), as manobras e intervenções de baixa invasividade no corpo, os procedimentos dietéticos conduzidos por um vínculo terapêutico reparador conduzem a uma reorganização energética e readequação do modo de vinculação com si mesmo e o mundo. Não tratam do sintoma especificamente como "problema", mas como sinais que nossa própria natureza nos convoca a olhar e cuidar, voltar-se para eles e reorientar a existência.

Estas práticas nos convocam tecer compreensões a partir de um paradigma energético, que diferente da objetividade professada pela racionalidade dominante, evocam a necessidade do autoconhecimento, do cuidado de si mesmo e do conhecimento construído a partir desta experiência de relação com si mesmo e o outro.

A dimensão vincular está fortemente presente nos estudos de Martins ${ }^{5,6}$, o autor aborda um enlaçamento no binômio energia-vínculo. Com base no referencial mausseano da dádiva ele sugere que o conceito de "energia", adotado nas PICS, serve como "operador simbólico" que conecta o homem a outro homem e com o meio ambiente. Aqui temos a energia-vínculo como configuradora do corpo e da organização da vida. É no exercício solidário de gratuidade e obrigação que as terapias, o terapeuta curador e o sujeito ou comunidade curada se vinculam. Esta operação traduz-se por um compromisso com a vida, em uma dimensão mais profunda com o bem comum, a medida que se instaura dentro de uma lógica dadivosa.

Por diversos enfoques ancorados em uma perspectiva energética/vitalista abrangente, as PICS convidam a construir uma consciência sobre os modos que nos vinculamos com si mesmo, com o outro, com a sociedade e a natureza de uma forma mais ampla. Este convite, mais ou menos efetivo prioriza de maneira diversa estes diferentes aspectos da vinculação, implica uma ética da sensibilidade, aprendendo com o cuidado na própria experiência viva.

Entretanto, antes de nos dedicar a este ponto específico, de uma ética da sensibilidade no cuidado humano, precisamos demarcar, como bem lembra $\mathrm{Luz}^{3}$ que há uma diversidade de sentidos e uma pluralidade de práticas no campo das PICS. Estas práticas encarnam distintos valores. Com 
ISSN 2179-6750

isto não queremos reduzir o campo em questão aos nossos argumentos e reflexões, nem realizar uma mera simplificação. Neste presente estudo, iremos centrar nas práticas terapêuticas que fazem contraponto a valores dominantes da cultura capitalista ou que explicitam ambiguidades nestes valores e que igualmente nos convocam para uma ética da sensibilidade, que não cuida apenas para minimizar a perturbação vital, mas aprofundar a integridade, "reiterar valores de uma vida 'harmoniosa no todo' isto é: equilibrada mental e fisicamente, solidária no plano familiar e social, não competitiva ou agressiva, descontraída, se não despreocupada, e, se não alegre, ao menos bemhumorada" ${ }^{3}$ (p. 41).

Este conjunto de práticas "não ortodoxas" intituladas por hora como PICS compõem as margens do campo da saúde, mas nossos argumentos, ao invés de se fixar nas polaridades (entre o núcleo e a periferia), se dá na existência viva, no testemunho do cuidado, que ocorre em uma “terceira margem", naquilo que não há, mas acontece ${ }^{7}$, no lugar hibrido da realidade que não distingue completamente estas fronteiras que compõem uma singularidade afetada por estas diferentes margens.

\section{Ética da sensibilidade e o cuidado nas PICS}

É justamente na dimensão ética do cuidado, mais especificamente uma "ética da sensibilidade", que atravessa o campo das PICS, que nos aprofundaremos nossa reflexão. Ao adotar o termo "ética da sensibilidade" podemos ser remetidos ao debate filosófico proposto por Feuerbach $^{8}$. Albinati ${ }^{9}$ comentadora da obra do autor nos diz que apesar de toda os limites do materialismo, naturalismo e sensualismo "o grande mérito de Feuerbach está na reposição da relação entre ser e pensar" (p. 83). Para o autor "a característica essencial de uma existência objectiva, de uma existência fora do pensamento ou da representação, é a sensibilidade ${ }^{8}$ (p. 9).

Uma ética da sensibilidade não significa, assim, um pieguismo da misericórdia ou uma arbitrariedade da vontade, como pensava Kant ao dizer da volubilidade da vontade diante das inclinações, mas um reconhecimento da sensibilidade que afirma o humano a partir da individualidade concreta, objetiva, correlacionada à objetividade. Os sentidos são as portas de apreensão da objetividade. $O$ amor é a afecção que traduz a dependência humana da objetividade, seja na forma dos seres naturais, seja na forma dos outros seres humanos ${ }^{9}(\mathrm{p}$. 82 , grifo nosso).

Uma ética da sensibilidade questiona a objetividade do racionalismo cartesiano e a ideia persistente de um homem abstrato cindido no pensamento e nas afecções. Questiona um pensar que destitui o ser em suas afecções, como se fosse possível uma assepsia dos sentimentos no ato de reflexão e de construção do conhecimento. A sensibilidade apela para o humano encarnado que vive, sente, pensa e age como ser. 
ISSN 2179-6750

Podemos observar no vitalismo europeu um apelo ao conhecimento sensível que emerge da experiência, um de seus maiores expoentes, Henri Bergson ${ }^{10}$, faz da intuição o caminho de acesso ao conhecimento que nos aproxima do interior da experiência. De certo modo, é possível ver na história de Samuel Hahnemann e de Edward Bach, com seus sistemas terapêuticos (homeopatia e florais) um conhecimento intuitivo construído a partir de uma profunda experiência sensível da vida. Um conhecimento sensível também está presente na obra de Goethe que inspira Rudolf Steiner no desenvolvimento da Antroposofia.

Almeida e Ribeiro Júnior ${ }^{11}$ com base no pensamento de Levinas propõe uma ética da sensibilidade do profissional da saúde que tem sua origem na motivação do face a face com o outro, que se traduz como uma maneira de humanizar o pensar e o agir do profissional da saúde em uma relação encarnada de cuidado com o outro.

Apesar da ética da sensibilidade surgir como tema na filosofia europeia e nestes sistemas médicos diversos nos séculos XIX e XX, podemos ver apontamentos desta ética nos escritos milenares do taoismo e do vedanta. Na obra de Lao Tsé ${ }^{12,13}$ no poema 18 vemos como o intelecto ou a inteligência racional está associada a uma perda de potência na vida, a desconexão com o Caminho, e seu resultado é a insinceridade ou hipocrisia. Um dos fatores desta desconexão é a falta de WU WEI (ação sem intenção), WU YEN (palavra sem intenção) e WU SZE (atitude sem apego). Esta afirmação taoista não é negadora do conhecimento, contudo faz crítica em relação ao modo como nos relacionamos com a vida, como agimos, dando sábios conselhos para uma sábia existência.

No "Amrita Bindu Upanishad" 14, podemos ver o seguinte pensamento: "A mente deve ser controlada para aquela dimensão no qual ele se funde no coração. Isto é Jnana (realização) e isto é Dhyana (meditação) também, tudo o mais é argumentação e palavreados” (p. 9). Nesta concepção a mente precisa ser controlada dentro do coração para que se livre dos seus apegos pelos objetos dos sentidos. O coração toma o lugar central no conhecimento. Se podemos dizer que nossa sociedade é cada vez mais cerebral, os escritos védicos sugerem que a morada central do conhecimento que realiza o humano em sua jornada está no coração.

Estes apontamentos diversos apenas abrem um campo de diálogo onde diferentes sistemas de pensamento e práticas de cuidado, convocam a sensibilidade humana como via ética para um conhecimento íntegro que auxilie na existência, em uma boa vida. Não é escopo de nosso trabalho realizar comparações entre estes diferentes sistemas de pensamento. $\mathrm{O}$ que queremos evidenciar é a via do conhecimento sensível que permeia a humanidade. Os sentidos; a compreensão sobre as emoções a percepção das afecções no corpo; o amor e sua dimensão ampla que engloba o próprio 
ISSN 2179-6750

conhecimento adequado da vida; a consciência de si; a relação com humanos, com os elementos da natureza e outros seres vivos; a multiplicidade de possibilidades terapêuticas que compõem estas relações. Todos estes aspectos tratam de um âmbito da sensibilidade que se ocupa com um ser humano, para além de suas demandas pragmáticas.

No campo prático das PICS, o cuidado humano à saúde aponta para uma ética que envolve a sensibilidade do profissional enquanto ser humano que se ocupa ou não com o cuidado de si, para de fato tornar-se melhor, e não apenas um reprodutor do Sistema da Doença e do Mercado ${ }^{15}$. Este é o dilema fatídico que os cuidadores se encontram no campo da saúde. Daqui parte a experiência que tomaremos como foco, a partir da vida que enfrenta este dilema existencial e testemunha em si mesmo uma moralidade sensível que resiste.

A ética da sensibilidade, presente no cuidado ofertado por diversas PICS, brota da experiência humana encarnada no lócus de terapeuta que recebe e oferta cuidados e se fortalece com os sistemas e práticas terapêuticas que persistem na dimensão sensível da vida. Como não podemos transformar a experiência em texto, adotaremos o testemunho como um recurso metodológico que nos aproxime dela e ajudará a penetrar nesta dimensão sensível.

\section{O testemunho como meio de compartilhar a experiência de cuidado sensível das PICS}

Não caberá no espaço deste artigo aprofundamento teórico acerca no testemunho enquanto método de pesquisa no âmbito das ciências humanas, bem como não poderemos aprofundar seus usos recentes e discutir as perspectivas comumente adotadas nas análises testemunhais, para este aspecto recomendamos a coletânea organizada por Seligman-Silva ${ }^{16}$ e o estudo atual realizado de Barreto ${ }^{17}$. Contudo faremos um breve comentário sobre estas questões e uma aproximação do testemunho no campo da saúde, mais em particular nossa opção por adotá-lo neste artigo como recurso para dar visibilidade a experiência do cuidado das PICS com foco na dimensão ética da relação e da sensibilidade humana.

O testemunho apresenta-se historicamente como uma peça icônica do dilema humano de gerar sentido na experiência, sobretudo quando se depara com situações-limites, ocupando o lugar de um valor elementar nas narrativas produzidas pelos sobreviventes de traumas e catástrofes ${ }^{18}$. Vale ressaltar, o interesse das ciências humanas pelo testemunho guarda uma relação direta com os acontecimentos cruciais vivenciados nas duas grandes guerras mundiais desencadeadas no início do século XX. Estas produções são conhecidas como literatura do testemunho.

A expressão literatura de testemunho comumente remete a uma relação entre literatura e violência do Estado. Há duas grandes concepções de literatura de testemunho que não dialogam 
ISSN 2179-6750

muito entre $\mathrm{si}^{19}$ : uma delas desenvolve-se no âmbito dos estudos sobre a literatura latinoamericana; a outra é dominante no campo da reflexão sobre a Shoah ${ }^{2}$. Ambas desenvolvem indagações sobre as possibilidades de a palavra representar a realidade.

É pelo contexto da experiência limite que o sofrimento humano nos convoca, bem como do desafio de representar a realidade (do itinerário e das relações de cuidado que trilhamos diante do sofrimento) através da palavra que o testemunho se faz presente neste trabalho.

O processo de cuidado humano, mas particularmente com as PICS, principia com um encontro. A saúde ou doença começa com uma relação com outrem - que seja inclusive si mesmo. Os processos de trabalho, as diversas estratégias terapêuticas, os recursos técnicos e formativos, todos esses elementos configuradores do cuidado são condições necessárias, mas não suficientes para desencadear uma experiência terapêutica - de cura, reestabelecimento, ou simplesmente, a experiência interior de sentir-se cuidado. Todo ato de cuidar pressupõe, antes de tudo, um estar junto, um modo de presentificação de sentidos que se manifesta quando se reconhece a voz do outro ${ }^{20}$, o toque, a presença. Quer dizer, quando se abre um espaço para uma alteridade diante da qual não se pode ser indiferente. Por essa razão, o cuidado com as PICS, entendido como processo de aprofundamento de si mesmo, melhoramento, formação humana, não pode se fundamentar meramente no intelecto, mas na relação expressiva e intensiva com o outro.

Como consequência, não faz sentido separar as dimensões epistêmicas, políticas, éticas ou estéticas, posto que o cuidado do humano emerge enraizado, encarnado na experiência, tecendo e entrecruzando relações múltiplas e complexas. Por esta perspectiva, as PICS são uma aposta emergente, uma resposta sistêmica em vista a prevalência de uma concepção técnico-mercadológica da racionalidade médica dominante que, cada vez mais, esforça-se para se legitimar em nome da própria ciência.

Paradoxalmente, a noção de experiência, embora considerada vital para o desenvolvimento das ciências humanas e da saúde, acabou se confundindo com experimentum, no meio acadêmico, durante o seu processo de institucionalização ${ }^{21}$. No mainstream acadêmico da saúde, as metodologias de pesquisas entendidas como padrão-ouro, tais como os ensaios clínicos duplo-cego randomizados, passam como se a experiência perturbasse o almejado desenvolvimento científico, desqualificando-a. Temos uma nulidade do "cuidador" aonde a relação/vínculo terapêutica não é considerada. $\mathrm{Ou}$, então o entendimento da presença do terapeuta como uma interferência a ser

\footnotetext{
${ }^{2}$ Termo hebraico que significa holocausto e concentra um cânone com diversos testemunhos, estudos e publicações em torno de judeus que sobreviveram aos campos de concentração na Segunda Grande Guerra, dentre eles estão Primo Levi, Paul Celan, Victor Klemperer, Georges Perec.
} 
ISSN 2179-6750

controlada. No aspecto mais extremo deste modelo, temos "a cura como mera relação químicomatemática dentro de um corpo máquina objetivo com algumas variáveis" ${ }^{22}$ (p. 306).

O apagamento dos aspectos experienciais nas reflexões científicas no campo da saúde, e mesmo filosóficas, remete diretamente a um contexto da saúde marcado por um discurso legitimado univocamente pelo saber-fazer em detrimento do saber-expressar e do saber-relacionar.

Contudo, a revelia deste rigor, mesmo com o esforço de colocar sob suspeição pelo discurso científico a experiência e o vínculo terapêutico - vemos uma emergência das PICS como bem sinalizada por Luz $^{3}$ e Martins ${ }^{5}$. Parte desta emergência se dá inclusive entre grupos culturais intelectualizados. Este fenômeno atravessa nosso continente e é bastante expressivo em países como a Suíça como aponta a Organização Mundial da Saúde ${ }^{21}$. O que estas duas margens nos convidam a ver? Qual a terceira margem? A experiência sensível - como dimensão fundamental do cuidado?

A experiência terapêutica e formativa, como acontecimento para além da relação sujeito e objeto, pode ser opcional pela própria epistemologia científica inaugurada pela modernidade. Entretanto, a vida em si não permite esta seletividade e, é neste âmbito que a legitimidade das PICS é irrefutável como modos do cuidado humano.

As PICS sustentam uma concepção de cuidado como aprofundamento de si, uma experiência formativa de si mesmo que aprimora a sensibilidade humana na vida prática e nutre o cuidado de sentidos potentes no tempo presente.

Ao nos debruçar para os serviços públicos de saúde e para as grandes universidades, é perceptível a hegemonia da racionalidade biomédica na formação das diversas áreas de saúde, bem como na oferta de cuidado em serviço. Entretanto, esta hegemonia não representa homogeneidade, bem como o fato de ter uma "formação convencional" na saúde não significa distanciar-se das PICS.

Em nossa experiência pessoal formativa, assim como temos percebido ao longo de mais de uma década de imersão no SUS, que as divergências aparentemente irreconciliáveis no plano teórico e científico da saúde, uma vez imersas nas dimensões experienciais, ético-estéticas e poéticas do cuidado no cotidiano da vida, procuram forjar um campo singular e plural de possibilidades terapêuticas para o cuidado humano, partindo das próprias ambivalências presentes na existência do terapeuta e dos usuários/comunidade que muitas vezes podem ser negligenciadas em sua potência por um estreitamento da experiência.

Nossa problematização adota o gesto singular do testemunho para transitar nesta zona ambivalente da realidade. A reflexão sobre o gesto de testemunhar parece ter-se ausentado da atividade do cuidador (em suas diversas formações na saúde), sintomatizando o instrumentalismo 
ISSN 2179-6750

da razão médica vigente na precariedade dos processos de trabalho, seja na prática clínica, na formação dos profissionais, seja ainda, nas tentativas de pensar e pesquisar a/na saúde.

Por outro lado, todo aquele que vivenciou o cuidado a partir das PICS ou que se tornou terapeuta de alguma(s) modalidade(s) das PICS testemunha o impacto destas experiências em sua vida, como geram sentidos e transformações - uma espécie de convite existencial para o aprofundamento de si mesmo. No campo das PICS semeia-se por diversos enfoques o cultivo de uma integridade, buscar e sustentar em vida o amor, a felicidade, a confiança, a harmonia e tantos outros objetivos que extrapolam simplesmente um bem-estar físico ou emocional. Temos um convite para um comprometimento com uma moral, que antes de pautar-se em algo transcendente ou estático que se perde no infinito horizonte - como pode parecer aos olhares (in)experientes -, se trata de uma moral tecida no cotidiano, que dá sentido ao movimento inerente da existência, e, se faz presente pela potência que traz em vida.

Considerado apenas como mais um gênero literário, o testemunho diz respeito, antes de tudo, a uma experiência feita de corpo presente: viu-se, ouviu-se, sentiu-se, ou seja, fez-se a experiência de algo que agora se busca transmitir. É legitimo e substancial dar voz aquele(a) que viveu uma experiência de corpo presente com as PICS, no esforço para transmitir o possível desta vivência. O testemunho fala, portanto, de um gesto intersubjetivo imanente a várias vivências, inclusive o cuidado. $\mathrm{O}$ ato de testemunhar adquire significado na medida em que acreditamos que alguém é capaz de dizer a verdade, confiando-se em um outro, na sua capacidade pura e simples de presenciar, e se a testemunha está engajada eticamente naquilo que diz o interlocutor também há de receber, com confiança, suas palavras, há de abandonar-se a um tipo de boa-fé básica, acolhendo a verdade de outrem. O testemunho é um acontecimento vital, uma espécie de paradigma das relações inter-humanas ${ }^{23}$.

O argumento que está sendo defendido não deixa dúvidas: a própria experiência da verdade, alvo tanto da atividade filosófica quanto da ciência, o ideal de verdade que alimenta nossas variadas abordagens de pesquisa, a validação de procedimentos clínicos e terapêuticos, por exemplo, depende, em última instância, de testemunhas. O testemunho é a condição que permite explicitar e certificar o ato pelo qual o real se torna verdade. Logo, a verdade não se impõe necessariamente com a evidência autônoma de uma dada construção teórica ou metodológica, configura-se como um regime existencial que sustenta o real, suporta-o e o garante, mas, também, às vezes, o subverte, alterando os modos instituídos da própria faculdade de conhecer.

O que sustenta a comunidade de cuidadores, cuidandos e escolas formadoras em PICS, para além de seus procedimentos mais ou menos aceitos por um paradigma dominante é o testemunho 
ISSN 2179-6750

daqueles/as que vivem a experiência e a tornam verdade.

Assim, a verdade testemunhal configura-se como um momento essencial na história dos sistemas de pensamento, desdobrando um modo singular de subjetivação ${ }^{24,25}$ tanto individual quanto coletivo, posto que ao tornar o mundo rememorável, presente e presenteado, o testemunho vale também como promessa de mundo; mundo a que se adere como se dele houvesse prova definitiva, embora elaborado na exposição recíproca de reconhecimentos mútuos e conflituosos.

Topamos aqui com um belo paradoxo para pensar o sentido da pesquisa e do cuidado com as práticas integrativas em saúde, e, de um modo mais amplo, pensar as pesquisas no grande campo da saúde: a constituição da verdade que se busca, colocada na dependência do testemunho, ele mesmo, um gesto propriamente inverificável. Logo, acreditar, refutar ou o mero permanecer cético diante dos poderes ou mesmo dos resultados passíveis de serem alcançados pela investigação ou nos trabalhos terapêuticos articulam-se como atos políticos-existenciais no sentido exato do termo, isto é, atos sem fundamentos absolutos.

A autoridade do testemunho repousa diretamente na linguagem dos sentidos, na linguagem do corpo próprio. Essa linguagem que universalmente fala em todos nós, mas que foi ofuscada da nossa consciência ou colocada sob uma vigilância epistemológica estridente, inclusive nas chamadas ciências humanas e sociais, bem como nas ciências da saúde. Por isso, o dilema metodológico que o testemunho coloca para as pesquisas acerca do cuidado humano não diz respeito apenas às dificuldades de traçar um limite seguro entre o testemunho e a ficção, nem em estabelecer a diferença efetiva entre uma ideologia e uma narrativa histórica. $\mathrm{O}$ desafio metodológico do testemunho radica, antes de tudo, no exercício público da coragem da franqueza.

Nas palavras de Pierron ${ }^{26}$, o testemunho é um modo de certificação existencial, que abre uma crítica contundente ao modelo de gestão técnica da vida humana, desvelando uma das maiores catástrofes do nosso tempo: a normalização operada pelas próprias ciências, incluindo a saúde, quando submetidas aos ditames produtivistas. Deste modo, a "terceira margem" buscada pela via testemunho neste estudo, pretende aproximar-se responsavelmente das múltiplas condições da experiência da perda controlada e resgate da humanidade do humano, dando ênfase à sensibilidade como dimensão ética do cuidado em PICS.

\section{Habitando este lugar da ambivalência: um testemunho de cuidado sensível}

O trabalho de cuidado no campo das PICS, em especial, o cuidado nesta zona do sensível, de uma ética da sensibilidade que se tece na vida prática, traz em seu bojo uma concepção de cuidado como formação de si mesmo - de um trabalho pessoal de melhoramento de si que aprimora e 
ISSN 2179-6750

cultiva a humanidade ao longo da existência alargando a sensibilidade de si mesmo. Vamos penetrar na experiência deste modo de cuidado através de dois testemunhos que nos ajudam a revelar

Contudo, é importante demarcar a zona de ambivalência de onde partem os dois testemunhos que iremos apresentar. O primeiro deles ocorre entre a periferia e o núcleo no campo da saúde, a experiência acontece no processo de formação, de tornar-se um psicoterapeuta corporal. O testemunho em questão foi extraído da tese de doutorado de Barreto ${ }^{17}$ aonde ele narra o seu processo de formação no campo da Psicologia Somática (este campo também pode ser definido de forma aproximada por outros termos: Body Psycotherapy, Body-Mind Medicine, Bodywork), em específico o autor vivera uma formação clínica em Análise Bioenergética, campo fundado por Alexander Lowen ${ }^{27,28}$ significativamente influenciado pelo trabalho clínico de Wilhelm Reich ${ }^{29,30}$. Se o campo da Psicologia Somática é considerado periférico-alternativo, o acessamos através de uma tese acadêmica de doutorado - que por sua vez faz parte do centro.

Lowen ${ }^{31}$ deixa claro o lugar de ambivalência que o fez construir o campo. Ele fala do inestimável valor de sua formação médica convencional, entretanto ressalta as lacunas e destaca a sua necessidade de um cuidado humano sensível:

\begin{abstract}
Quando ingressei na faculdade de medicina aos 36 anos de idade, eu havia sido aluno de Wilhelm Reich e já trabalhara como terapeuta durante alguns anos. Queria aprender mais a respeito do corpo e das doenças que nos afetam, mas queria adquirir esta compreensão em termos humanos. Mais especificamente, eu tinha vontade de saber que papel os sentimentos desempenhavam na saúde e nas doenças e como poderíamos explicar o amor, a coragem, a dignidade e a beleza. Embora os conhecimentos obtidos na faculdade de medicina tenham se revelado de inestimável valor, os termos que acabei de citar infelizmente jamais foram mencionados lá, e nem tampouco encontrei qualquer referência a eles nos compêndios médicos ${ }^{31}$ (p. 33).
\end{abstract}

O testemunho a seguir é de alguém que igualmente teve uma formação acadêmica convencional no campo da Psicologia e em outras áreas das ciências humanas (Antropologia e Educação), e, eventos diversos da vida - com destaque para a necessidade de um cuidado de si desperto por sofrimentos ocasionados em seus processos de formação educacional, sua dificuldade pessoal com seus relacionamentos, bem como os desafios evidenciados no campo da prática profissional junto a movimentos sociais e serviços públicos - o levou de algum modo a este caminho. Neste artigo será exposto um trecho de seu testemunho que dá ênfase ao modo como foi experienciado a sua formação clínica em Análise Bioenergética. Lembramos que neste momento o autor já possuía um bacharelado e uma habilitação em Psicologia, bem como um mestrado em Antropologia. Isto é importante demarcar, pois é no que foi inexpressivo e faltou no processo de formação universitário, que está o foco de sua busca - nem por isto, menos fundamental. O trânsito entre periferia e núcleo vai tecendo uma terceira margem que compõe uma síntese singular de 
ISSN 2179-6750

cuidado e formação. O que veremos então é a ênfase no processo de sensibilização do autor, em uma imersão de autoconhecimento compartilhada por pares e mediada por terapeutas mais experientes, que não tem uma função de "contradizer" o conhecimento anterior, mas avançar no conhecimento acerca da saúde e do humano por outro modo ${ }^{7}$.

Nas experiências que vivi, havia uma singularidade que convocava a minha presença humana. Geralmente era assim que iniciávamos os encontros pedagógicos: era conduzida alguma techné (o mais artesanal possível) que nos convocava a presença: a maioria das vezes via práticas de respiração e meditação, silêncio e atenção interior.

Em seguida, ouvia-se a todos (em alguns casos esta escuta poderia durar uma manhã inteira por ser ela e os trabalhos desdobrados desta escuta o material pedagógico privilegiado de trabalho). Assim, simplesmente, conectávamo-nos uns aos outros, reconhecendo o percurso que cada um teve até chegar lá, os dramas íntimos que habitam cada singularidade. Esta era a realidade do grupo que se revelava à medida que éramos convidados a nos expor com nossa presença, tecíamos um laço de fé naquela relação, uma confiança para sermos verdadeiros com as coisas mais difíceis e agradáveis de nossa Vida, mesmo em um mundo onde aprendemos por muitas vezes a guardar até de si próprio, a dor e a alegria. A Vida de cada um já era matéria prima de conhecimento.

Sempre havia trabalhos corporais, seja através do cuidado psicoterapêutico em grupo, dos exercícios de bioenergética ou outros recursos complementares como, por exemplo, a dança. Eu tinha a oportunidade, caso necessitasse, de ter a atenção de todo o grupo para compartilhar a experiência singular de si mesmo. Os outros membros grupo também faziam uso deste espaço quando necessário. Progressivamente íamos conquistando maior autonomia para o cuidado. Inicialmente sempre havia a condução de nossos mestres, em seguida passávamos a realizar algumas atividades no grupo com a presença deles. Ficávamos sob a supervisão dos professores e também amparados por todos do grupo. O trabalho fluía intensamente com uma atmosfera contínua de segurança e cooperação.

Conflitos íntimos e relacionais envolvendo filhos, companheiro/a, pais. Histórias de traição, violência sexual e abuso. Morte, desemprego, conquistas, frustrações, separações. Tudo emergia com naturalidade, nosso corpo progressivamente ia afrouxando as couraças como uma expressão natural do cultivo da fé, a partir da realidade de nós mesmos. Éramos acolhidos na tristeza e na dor, encorajados a lidar com o medo e o vazio existencial. Tínhamos suporte para lidar com a raiva e o ódio. Fomos estimulados na alegria e no prazer. Tudo através do trabalho corporal consciente, regido por nosso self, abríamos nosso coração em ambiente seguro, podíamos nos entregar progressivamente as emoções e às sensações. Por mais difíceis e dolorosos que fossem os trabalhos pessoais, ao final de uma jornada de trabalho, repercutia no íntimo de cada ser e na atmosfera do ambiente uma felicidade espontânea e lúcida. A felicidade entendida como "consciência de crescimento ${ }^{28}$. Esta conclusão era de fácil percepção, pois os trabalhos eram finalizados sempre com avaliações pessoais compartilhadas em grupo que referendam este ponto de vista.

Um laço de profunda fé e amor operou inúmeros reparos na Vida de todos os presentes. Eu particularmente passei encontros no qual eu me debati contra almofadas e colchões, ou, utilizei uma raquete de tênis para surrar almofadas - expressando corporalmente de forma segura e na intensidade necessária, a raiva tão presente na obscuridade de minha Vida...

192 


\section{ISSN 2179-6750}

Para Lowen ${ }^{32}$ a raiva “[...] é uma força de vida positiva que tem fortes propriedades curativas" (p. 91). Podemos defini-la como uma emoção (nos termos reichianos) natural “[...] que serve para manter e proteger a integridade física e psicológica do organismo" 32 (p. 85). Só em corpos relativamente livres das tensões decorrentes da contenção de raivas não expressas, que o amor pode fluir de modo mais profundo e verdadeiro, pois nesta relação há lugar para a autêntica expressão do self ${ }^{32}$.

Em outros encontros eu chorava visceralmente, às vezes por cerca de uma hora, urros e lágrimas jorravam de minha boca e olhos. A minha dor e tristeza pareciam sem fundo, unia-se à dor do mundo e das pessoas com as quais eu trabalhava (na época acompanhando adolescentes infratores e moradores de rua) ${ }^{3}$.

Chorar é uma expressão primária "[...] de descarga da sensação de coração partido" 33 (p. 66). Chorar diante da tristeza da Vida é "[...] a aceitação da realidade tanto do presente como do passado" ${ }^{32}$ (p. 46). Inibir o choro nestas ocasiões é conseguida às custas da contenção respiratória. Enquanto a respiração for superficial qualquer discussão sobre os problemas pessoais permanecerá um "exercício intelectual incapaz de atingir sensações e sentimentos mais profundos" 33 (p. 66). "O choro alivia nossa tensão corporal, aumenta a capacidade respiratória e energética para reagir diante do mundo, fortalecendo a voz" ${ }^{33}$ (p. 66).

Em outros momentos, pude lidar de modo libertador com minha sexualidade, trabalhando minhas repressões, bem como permitindo sentir um prazer e uma alegria genuína que me permitia trazer um riso leve e rítmico, cantar, dançar, permitir-me expandir com a graciosidade destes estados. Pude sentir uma vibração circulando todo o meu corpo e uma excitação profundamente prazerosa que me preenchia internamente.

Houve também encontros nos quais o medo se revelou em mim, congelava-me, mãos e pés ficavam duros e frios. Com suporte do grupo, recebia um cobertor ou um colo humano - que me encorajava com o toque terno e amoroso. Eu podia olhar o medo, entender seu fundamento, integrá-lo em minha história, me aquecer e seguir a Vida mesmo diante dele...

O modo respeitoso, empático e atencioso com que cada um era tratado tocava a todos nós. E, as histórias, vividas por cada um, ecoavam na intimidade de nossa condição humana de modo que muitas vezes me dispondo a cuidar, aprendia tanto ou mais do que sendo cuidado. Ou, às vezes, apenas sendo um espectador silencioso, preservando uma atitude respeito e empatia com a experiência que o outro revelava, eu era lançado as profundezas de mim mesmo. Estas polaridades (de cuidar e ser cuidado; de ativo e passivo), em certo sentido, diluíam-se pelo próprio vínculo amoroso que integra...

Estas aprendizagens que tive ao longo destes anos, não me transformaram em alguém plenamente realizado (na verdade, talvez tenha mais clareza de quão longe estou disto), mas fez-me consciente de minhas fragilidades e ávido por mais descobertas edificantes em um terreno de resistência humana, buscando lidar com as ambiguidades de meu ser na Vida cotidiana ${ }^{17}$ (p.120).

Este trecho do testemunho permitiria aprofundar vários elementos que se referem a fundamentos teóricos e técnicos do trabalho específico, mas não cabe aqui debater tais aspectos que fogem ao escopo deste estudo. Recomendamos a leitura da própria tese ${ }^{17}$ para quem deseja

\footnotetext{
${ }^{3}$ No capítulo anterior já pude relatar um pouco da realidade que vivi com estes trabalhos. Como no ambiente institucional pouco podíamos expressar nossa dor diante destes episódios de perdas, no Libertas eu podia ser reconhecido e podia mergulhar na profundidade da impotência que me rondava.
} 
ISSN 2179-6750

aprofundar em questões especificas do campo. Como tomamos de empréstimo este testemunho para uma discussão mais ampla da dimensão ética do cuidado nas PICS iremos destacar três aspectos que apontam para uma possível ética da sensibilidade humana: o vínculo seguro; o trabalho de si, $e$ a experiência de cuidado encarnada.

$\mathrm{O}$ vínculo seguro que favorece uma experiência de confiança e solidariedade que permite penetrar na verdade de si mesmo. Este ambiente, longe de ser algo "mágico" dado a priori, é construído passo a passo através de alguns recursos técnicos e humanos. Alguns trabalhos corporais que envolvem respiração e autopercepção aliado ao diálogo direcionam para o exercício da presença de si mesmo e a disposição íntima e objetiva (à medida que se dá tempo e espaço) de ocupar-se com o outro. Estes dois fatores, aliados a uma atitude empática, parecem moldar a humanidade dos terapeutas em formação. A lição passada, de modo mais ou menos explicita, é que para o cuidado é necessário estabelecer um vínculo seguro. E, para que este vínculo seja realmente seguro, é indispensável presença de si mesmo, a disposição íntima e objetiva de ocupar-se com o outro que solicita o cuidado, bem como sustentar uma empatia nesta relação. Ora, como aprender estes aspectos e fazer uso destes recursos senão vivendo-os?

O que vimos no testemunho é como a formação em questão tem um trabalho intensivo para tratar dos afetos envolvidos nas relações humanos, há uma contínua dedicação nesta dimensão sensível. Ocupa-se com a lacuna deixada pelo modelo hegemônico da racionalidade biomédica como enfatizado no início de nosso trabalho ${ }^{3,4,5,6}$. Medo, tristeza, raiva, prazer e alegria são emoções que se tornam "conteúdo vivo" do processo de formação, passam a ser trabalhadas cuidadosamente - são visitadas em si mesmo. Este trabalho sensível faz uma diferença significativa para aqueles que vivem a experiência, dando segurança necessária para reconhecerem suas emoções, exercitarem sua sensibilidade e experimentarem modos de manejá-las para potencializar o autoconhecimento e a própria existência.

Sentir, expressar e refletir sobre a experiência de si, podem ser até irrelevante para a formação convencional que prioriza a segurança externa do domínio de teóricas, técnicas, protocolos, legislações e tantos recursos confiáveis, mas que se distanciam, tangenciando da verdade do que sentimos e vivemos e como cuidar dos vínculos a partir do vivido e da própria relação. Mas, é também esta própria formação convencional que através do campo das neurociências ${ }^{34}$ retorna a esta questão do vínculo e do ambiente seguro como determinante no tratamento de inúmeras patologias que interferem nas relações humanas.

Esta ética da sensibilidade no cuidado parece ser moldada por um caminho orientado à experiência, transformando as relações humanas e as afetações em si "objetos" de reflexão e 194 
ISSN 2179-6750

conhecimento. Deste modo, penetramos no segundo aspecto que envolve o trabalho de si. Não basta um exercício intelectual, um aprofundamento teórico, nem mesmo uma experiência prática de intervenção no outro. Como lembra Reich ${ }^{30}$, nosso intelecto está muitas vezes a serviço da dissociação da realidade ao invés de vê-la com maior verdade. Não é algo que passa apenas por uma apropriação de um papel profissional. É um trabalho que envolve si mesmo, a própria humanidade, é uma formação que nos indaga sobre a nossa existência e o que fazemos com ela. Somos convidados a revisitar eventos que moldam nossa existência, penetrar nas entranhas do que sentimos, de emoções que são muitas vezes ofuscadas no exercício de nossas funções sociais, mas que nem por isto são menos determinantes em nossas ações, bem como em nosso modo de existir.

É deste lugar de olhar, cuidar e realizar práticas que nos convidem a aprimorar si mesmo, a penetrar e cultivar a nossa própria humanidade que nos lançam para um espaço muitas vezes negligenciado na formação acadêmica convencional dos profissionais de saúde. Esta lacuna, que pode ser pouco referendada do ponto de vista da importância científica, no plano prático, em uma empiria da própria vida, ela se mostra inverossímil. É neste lugar da existência viva que temos que nos haver com si mesmos, e em última instancia não somos profissionais de saúde, mais sim humanos (mais ou menos trabalhados em nossa humanidade) que ofertamos cuidados aos outros que buscam amparo e sentido para seu sofrimento - uma resposta tangível à sua própria vida.

O último aspecto que pretendemos destacar neste testemunho que se refere à experiência de cuidado encarnada. É neste lugar da experiência interna de quem recebeu o cuidado que há a confirmação ou não da prestação recebida. Em última instancia não é a consulta ou determinado exame que dará o veredicto do cuidado, estes procedimentos podem acontecer, mas sem uma confirmação interna de cuidado pelo buscador desta assistência, não há em definitivo a experiência presente de cuidado. Pode haver uma assistência à saúde que não atinge a necessidade humana de amparo diante do sofrimento. Por este motivo, a experiência encarnada de cuidado existe a revelia dos papeis sociais que desempenhados, não se reduz a qualquer função que venhamos a executar, ela acontece apesar disso, quando há um encontro humano, uma relação que se sustente em um vínculo seguro, com a presença de si mesmo e uma disposição intima e objetiva do terapeuta em ocupar com o outro com quem demanda cuidado.

A experiência encarnada de cuidado não é definida por metas ou objetivos, apesar destas questões terem certo valor, ela simplesmente acontece por uma busca de aprimoramento da humanidade, os resultados deste encontro podem atingir as expectativas, mas via de regra, quando esta experiência acontece o produto deste encontro é surpreendente, por destoar de ganhos específicos. Não é apenas um ganho em relação à condição de saúde-doença que está posto. É um 
ISSN 2179-6750

ganho humano e existencial que lida com a totalidade do ser, ele pode acontecer mesmo em um processo onde o sintoma é irreversível.

Fundamentalmente, em uma ética da sensibilidade nos parece que é uma intensidade amorosa por si mesmo e pelo outro que modera esta experiência encarnada de cuidado. $\mathrm{O}$ cultivo e a sustentação de um vínculo humano amoroso são seu horizonte.

Posto as dimensões do vínculo seguro, do trabalho de si e a experiência de cuidado encarnada, vale frisar novamente este lugar habitado pela testemunha. Por mais alternativa ou periférica que seja sua busca formativa no campo das PICS, ela se dá em um diálogo continuo entre centro e periferia do campo da saúde, esta ponte que pode ser feita partir de aproximações teóricas mais ou menos aceitas no establishment acadêmico. Mas, sobretudo, ocorre no plano prático da vida cotidiana daqueles envolvidos com os processos de formação, assistência, gestão e pesquisa na saúde.

\section{Da transferência e permanência do cuidado sensível}

Para que haja a permanência do cuidado atento a uma dimensão ética da sensibilidade é necessária a transferência deste(s) modos de cuidado entre as gerações. Há que se cultivá-lo de forma viva, para perpetuar, durar ao longo do tempo e espaço. O testemunho, neste sentido, é um exercício simultâneo de cuidado ético, modo de experienciar a vida que se concretiza em ato no cotidiano da existência do pesquisador-cuidador, e, ferramenta de atualização de uma memória que preserva e persiste em eventos que nutrem uma verdade existencial forjada na própria singularidade vivida no contexto da saúde - neste caso o trabalho sensível com as PICS.

Adotamos o testemunho como um método de investigação autoral que se inclina diretamente para uma transmissão ocupada e preocupada em cultivar eticamente a busca de coerência dos vínculos inter-humanos. Cabe enfatizar, entretanto, que o termo transmissão adotado aqui não se trata de uma transmissão estática ou passiva de conhecimentos. A transmissão testemunhal, ao contrário, procura fazer entender as questões que contam enquanto questões vivas, destacando a interrogação e a intuição que faz depender o acesso à verdade de um trabalho formativo e de cuidado sobre $\mathrm{si}^{26}$. No pensamento freireano é possível localizar um acento na transmissão testemunhal, quando destaca a necessidade do educador corporificar as palavras pelo exemplo: "não há pensar certo fora de uma prática testemunhal que re-diz em lugar de desdizê-lo" ${ }^{35}$ (p. 34).

Neste segundo testemunho damos ênfase na transmissão, naquilo que faz viver as PICS ao longo do tempo. Reafirmando o nosso lócus da ambivalência, na terceira margem, o testemunho que segue abaixo se deu dentro do processo de formação acadêmico de Psicologia, em um 196 
ISSN 2179-6750

componente disciplinar do curso de graduação onde estudantes puderam ter acesso à Psicologia Somática. Ele foi retirado de uma fanpage do Facebook intitulada "Testemunhos da formação humana na saúde" que contem inúmeros textos produzidos por alunos que desejaram compartilhar suas experiências de nosso trabalho. Este trabalho que foi conduzido pelo autor do primeiro testemunho revela uma transmissão do conhecimento recebida anteriormente. Ao compartilhar o campo da Psicologia Somática com acadêmicos em formação, em um curto trabalho de trinta horas, foi possível para eles um reconhecimento inicial vívido desta área.

A redução da vida profissional e acadêmica aos modelos dominantes de excelência e qualidade, com base em competências e habilidades, vem produzindo efeitos nefastos para os processos de vinculação apropriados a todo trabalho de cuidado, gerando exigências (des)humanas que associam-se a frustrações, adoecimentos, conflitos interpessoais recorrentes que alimentam um sentimento crescente de insegurança e impotência. Muitas vezes, o resultado visível é uma dessensibilização nos processos de trabalho e cuidado humano.

No entanto, como indica Agamben ${ }^{36}$, nada produz tão poucos humanos livres como o estranhamento da sua própria impotência, pois "aquele que é separado do que pode fazer, pode, todavia, resistir ainda, pode ainda não fazer” (p. 59). Mas, aquele que é separado da sua impotência "perde em contrapartida, antes do mais, a capacidade de resistir". Assim, o testemunho que traremos aposta que uma visão lúcida do que podemos (não) ser e do que podemos (não) fazer, garante a verdade do que somos, criando condições para a emergência de uma compreensão ética da sensibilidade e política do nosso agir. Através do reconhecimento do medo, da tristeza e das fraturas íntimas, cuidando da insegurança e da impotência que fazemos nosso trabalho humano. A experiência singular vivida por um estudante em um dia marcante de trabalho, nos auxilia a penetrar na dimensão sutil, sensível e potente deste trabalho.

O meu relato é datado do dia 18 de julho, no mesmo dia em que aconteceu algo grandioso. Nesse mesmo dia eu decidi exprimir em letras o afeto pelo qual fui tomado, e até mesmo devorado. Assim, tive a tradicional conversa com o diário que todos imaginariamente têm, e que o guardam em seus níveis mais seguros de lembranças. De antemão, peço desculpas aos que ouvem pela crueza das palavras. Mas o que eu senti aquele dia, me demorou outros tantos dias para ser inteiramente digerido. Eis que segue:

“Meu caríssimo diário, repleto de ‘eu mesmo’ por mim, hoje eu passei por algo que jamais imaginei passar. Hoje eu chorei porque me confrontei com o silêncio de mim mesmo. Hoje eu chorei porque vi o meu corpo despido de tudo e de todos, e sinceramente, me fez sentir mais leve.

Vamos ao Cronos.

No meio de uma dinâmica de grupo eu deveria olhar o outro nos olhos e só.

Logo pensei "puta merda, que coisa invasiva". Eu tive razão. 
ISSN 2179-6750

Eu enfrentei o medo e fui com uma grande amiga. Que mal teria de olhar nos olhos de alguém que já olho tanto? Perdi a razão.

Foi uma invasão de coisas. Uma invasão de coisas interiores saindo de mim. Os sentimentos invadiram o lado de fora, se é que isso é possível. Contornei as lágrimas, segurei o choro, tapeei com o riso e abafei com um abraço em modo de porto seguro.

E foi assim que segui por todos aqueles que olhei os olhos. Entretanto, eles continuaram se fazendo de espelho para minha podridão, para minha desolação, o meu próprio abandono. Um abandono ou dois, silenciado e velado por um corpo que se fez de templo em adorno, apenas para desviar o foco, como se fosse uma couraça, que desvia e enfraquece os golpes do mundo (Reich, $1945^{4}$, citado por Helfaer ${ }^{37}$ ).

Nesse momento o meu corpo sentiu o peso de algo resguardado, algo tão meu quanto do mundo, do tempo e dos desejos. Falo do lugar de uma criança que a vida inteira não conseguiu olhar nos olhos de alguém por ter vergonha de si, por acreditar ser vergonha também. Falo do lugar de uma criança que foi abusada e forçada a esconder, porque aos 6 anos, se ela gostava daquilo, ela era uma aberração. Mas ela gostava daquilo? Falo do lugar de um jovem que chegou à beira da morte por ter sido abandonado por um amor. Abandonado? Aqui se fala de um lócus que foi despudorado, de uma inocência que foi violada, de uma infância que foi manchada. Peço desculpas, diário, por estar encharcando-o de lembranças tão ruins, mas foram elas que emergiram hoje. O que se escondeu a vida toda, o que eu escondi, foram as marcas quase que chagas de um sujeito que se fez pequeno por não saber lutar, e então quando pôde, se fez calar por não saber para onde iria sem os seus sintomas. E com seus sintomas, novamente se escondeu do mundo, buscando ser o menos humano possível, para não sentir a dor de suas perdas. Aqueles que não sabem o que vela o tecido, não sabem também o que marca a carne. Aqueles que não conhece as cicatrizes, julga mal o abraço que é negado e reservado. Paradoxo... O silêncio que muito diz por mostrar de fato a língua que fala o corpo. Um movimento que é expressivo, 'que vai além das limitações da linguagem’ ${ }^{30}$ (p. 333). Hoje eu vivi extremos. Vivi a vida e a morte, com o sabor agridoce que sempre fiz de significante pessoal. Mas me encontrei docemente com um certo alguém em meio a uma certa ressonância. Toda gratidão do mundo para aquele abraço que foi bem dado, porque eu estava em pedaços, e esse alguém me foi cola. Esse alguém, que eu sei que ela sabe bem quem ela é foi capaz de me juntar de novo e me fazer respirar, trazendo de volta os movimentos de sobrevivência do meu corpo - respira, inspira, expira.

Àqueles que me causaram como sujeito, todo afeto do mundo.

Por mais pessoas que sejam capazes de despir o outro de sua trama desordenada de mentiras e os faça cair em sua própria verdade.

Parece doloroso, mas é.

Pareceu doer, mas foi revelador

Aliás, a vida se constitui de uma gama de coisas que não se sabem e fingimos não ver.

De modo singular temos o testemunho de um estudante que fez contato com suas experiências dolorosas de violência e abuso sexual em sua infância. Este contato, que emergiu de modo espontâneo em um trabalho que tinha como foco o fortalecimento do vínculo seguro no grupo. Sua fragilidade, tristeza, insegurança e impotência foram acolhidas no trabalho, dando a

\footnotetext{
${ }^{4}$ Reich W. Character Analysis. New York: Farrar, Strus ans Giroux; 1945.
} 
ISSN 2179-6750

continência suficiente para que a experiência de si mesmo acontecesse de modo sensível e profundo.

O cultivo de um ambiente seguro, o trabalho de si mesmo e a experiência encarnada de cuidado no processo de formação na saúde vivido por este acadêmico foi uma extensão do território traçado anteriormente pelo cuidador-professor, favorecendo uma ocupação de si mesmo e a partilha de uma ética da sensibilidade no processo de formação e cuidado em saúde.

Esta transmissão testemunhal faz-se não apenas pela palavra, mas pelo corpo, integrando no ato de cuidado que engloba as sensações, as emoções e as possibilidades expressivas. A transmissão testemunhal é frágil, revela a fragilidade humana, já que é apenas um momento crítico, onde não há garantias de que sua transmissão se sucederá no tempo. Entretanto pelo seu valor existencial ela responde de modo assertivo aos anseios de uma vida viva ${ }^{17,26}$. Desta forma, ela se configura como um apelo vivo à humanidade. Sem esse apelo as intuições cuidadoras se fixam em instituições monumentais, morrendo lentamente pela falta de testemunhas. Assim como a sensibilidade humana esvai-se diante das exigências deshumanas de nossa cultura.

\section{Conclusão}

Neste artigo demos ênfase ao valor das PICS por ser encontrado no interior de seu campo uma ética da sensibilidade no cuidado. Como vimos, para além de fazer um contraponto da noção de experiência presente no espectro hegemônico da racionalidade biomédica que impõem condições doxológicas negadoras da relação humana de cuidado entre terapeuta e usuário, as PICS pluralizam este discurso, possibilitam revelar que existe no interior do campo da saúde, com maior ou menor rigidez, uma terceira margem válida: a experiência do cotidiano da vida de quem recebe e ofertar cuidados - ocupam-se com a humanidade.

Procuramos apontar três dimensões de uma ética da sensibilidade: o vínculo seguro, o trabalho de si e a experiência encarnada de cuidado. Igualmente importante é o modo como se dá a transferência de conhecimento, sendo um cuidador/educador que a transfere de modo igualmente sensível ao recebido.

O testemunho ajuda a operar uma inteligência sensível que, por sua vez, gera uma transmissão viva, integrando o inteligível, o sensível, o prático e o poético, através da singularização da experiência vivida. Isso justifica o argumento de que a pesquisa testemunhal não se reduz apenas a esta experiência e ao campo específico da Psicologia Somática. A seu modo ele permite aproximações e questões para o campo mais amplo das PICs, e em especial apontar a dimensão ética da sensibilidade no cuidado humano. 
ISSN 2179-6750

Nosso argumento se fez deste modo, pelo limite existencial dos próprios pesquisadores, o campo das PICs são experiências singulares de uma pluralidade de modos de cuidado, cada um com suas especificidades e sistemas interpretativos, mais ou menos complexos, mais ou menos afins. Entretanto, nossa aposta é que do ponto de vista de uma ética e política, respeitadas as diferenças, existe uma potência no campo das PICs que sinaliza para a sensibilidade humana. Seria valioso poder estudar como diversas práticas cultivam e aprimoram sensibilidades humanas específicas.

Diferentemente de outras metodologias de investigação científicas, o testemunho se pauta por uma verdade existencial, que apesar de ser frágil do ponto de vista das provações objetivas, é essencial para a construção de sentidos no existir humano. O testemunho apresenta-se, dessa ótica, como um método capaz de verdade, mas uma verdade que resiste ao processo de tecnificação da vida e de redução do horizonte da saúde e da formação humana.

Como não há verdades absolutas expostas no testemunho, a ética da sensibilidade é um campo que sempre recomeça. Para que as PICS se sustentem como um movimento humano no campo da saúde de preservação da sensibilidade humana, é necessário que esta ação de sustentação da sensibilidade seja atualizada diariamente por seus cuidadores, seja na oferta ou na recepção destes cuidados. É necessário comprovar em ato e em vida o que se propõem. A medida que sua institucionalização vai se fortalecendo no interior da sociedade, mas ambiguidades se revelam neste campo, igualmente surgem maiores desafios para se sustentar uma ética da sensibilidade que não seja capturada ou vendida, que não vire apenas um produto em nosso sistema social.

Seguir debatendo uma ética da sensibilidade também parece um desafio, vale aprofundar a reflexão, questionar se há validade epistemológica, política e empírica no campo da saúde para o que nos ocupamos neste trabalho.

\section{Referências}

1. Luz MT, Barros NF, organizador. Racionalidades médicas e práticas integrativas em saúde: estudos teóricos e empíricos. 1a ed. Rio de Janeiro: CEPESC; 2012.

2. Barreto AF, organizador. Práticas Integrativas em Saúde: proposições teóricas e experiências na saúde e educação. Recife: Editora UFPE; 2014.

3. Luz M.T. Novas Práticas em Saúde Coletiva. In: Minayo MCS, Coimbra Jr. CEA, organizadores. Críticas e atuantes: ciências sociais e humanas em saúde na América Latina. Rio de Janeiro: Editora FIOCRUZ; 2005. p. 33-46. 
ISSN 2179-6750

4. Pelizzoli, M. Saúde e mudança de paradigma: desafios da medicina tecnológica e da cura natural. In: Pelizzoli M, Liimaa W, organizadores. O ponto de mutação da saúde: a integração mente-corpo. Recife: Editora da UFPE; 2009. p. 299-319.

5. Martins PH. Contra a desumanização da medicina: crítica sociológica das práticas médicas modernas. 1. ed. Petrópolis, RJ: Vozes; 2003.

6. Martins, P.H. As outras medicinas e o paradigma energético. In: Luz MT, Barros NF, organizadores. Racionalidades médicas e práticas integrativas em saúde: estudos teóricos e empíricos. 1a ed. Rio de Janeiro: CEPESC; 2012. p. 309-42.

7. Barros NF. Práticas Integrativas em Saúde: a margem, o núcleo e a ambivalência. In: Barreto AF, organizador. Práticas Integrativas em Saúde: proposições teóricas e experiências na saúde e educação. Recife: Editora UFPE; 2014. p. 49-60.

8. Feuerbach L. Princípios da filosofia do futuro. Covilhã: LusoSofia Press; 2008.

9. Albinati AS. Feuerbach: fundamentos para uma ética da sensibilidade. Rev Dialectus. 2015;2(6):75-84, 2015. http://dx.doi.org/10.30611/2015n6id5204.

10. Bergson H. A intuição filosófica. Lisboa: Colibri; 1994.

11. Almeida DV, Ribeiro Júnior N. A sensibilidade e a humanização dos cuidados em saúde a partir da relação ética com o Rosto do Outro. Mundo Saude. 2012;36(3):407-15.

12. Lao-Tsé. Tao te ching: o livro que revela Deus. Rodhen H, tradutor. São Paulo: Alvorada; 1982.

13. Lao-Tse. Tao te ching: o livro do caminho e da virtude. Rio de Janeiro: Sociedade Taoísta do Brasil; 2012.

14. Upanishads [Krishna Yajur Veda]. Rio de Janeiro: [editora desconhecida]; 2009. Amrita Bindu Upanishad; [acessado em 9 abr 2017]; p. 8-11. Disponível em: http://www.shri-yogadevi.org/textos/Upanishads-Krishna-Yajur-Veda-port.pdf

15. Pelizzoli M. Visão histórica e sistêmica: bases para o paradigma integrativo em Saúde. In: Barreto AF, organizador. Práticas Integrativas em Saúde: proposições teóricas e experiências na saúde e educação. Recife: Editora UFPE; 2014. p. 23-48.

16. Seligmann-Silva M, organizadora. História, memória, literatura: o testemunho na era das catástrofes. Campinas: Editora UNICAMP; 2003.

17. Barreto AF. Pedagogia da vida: um testemunho da formação humana a partir das contribuições de Reich e Lowen [tese]. Recife: Universidade Federal de Pernambuco; 2016. 
ISSN 2179-6750

18. Seligmann-Silva M. Narrar o trauma: a questão dos testemunhos de catástrofes históricas. Psicol Clin. 2008;20(1):65-82. http://dx.doi.org/10.1590/S010356652008000100005 .

19. Marco V. A literatura de testemunho e a violência de Estado. Lua Nova. 2004;(62):45-68.

20. Bensussan, G. Ética e experiência: a política em Levinas. Carrara OV, tradutor. Passo Fundo: IFIBE, 2009.

21. Pagni PA, Gelamo RP, organizadores. Experiência, educação e contemporaneidade. Marília: Poiésis Editora; 2010.

22. Organização Mundial de la Salud. Estrategia de la OMS sobre medicina tradicional 20142023. Ginebra: OMS; 2013.

23. Kolleritz F. Testemunho, juízo político e história. Rev Bras Hist. 2004 dez;24(48):73-100. http://dx.doi.org/10.1590/S0102-01882004000200004.

24. Foucault M. Discurso y verdad en la antigua Grecia. Barcelona: Ediciones Paidós; 2004.

25. Foucault M. A coragem da verdade: o governo de si e dos outros II: curso no Collège de France (1983-1984). São Paulo: Martins Fontes; 2011.

26. Pierron JP. Transmissão: uma filosofia do testemunho. São Paulo: Edições Loyola; 2010.

27. Lowen A. O corpo em terapia: a abordagem Bioenergética. São Paulo: Summus; 1977.

28. Lowen A. Bioenergética. São Paulo: Summus; 1982.

29. Reich W. A função do orgasmo. São Paulo: Brasiliense; 2004.

30. Reich W. Análise de Caráter. São Paulo: Martins Fontes; 1998.

31. Lowen A. A espiritualidade do corpo: bioenergética para a beleza e a harmonia. São Paulo: Summus; 1995.

32. Lowen A. Alegria: entrega ao corpo e à vida. São Paulo: Summus; 1997.

33. Lowen A. Amor, sexo e seu coração. São Paulo: Summus; 1990.

34. Schroeter V. Polyvagal Theory. The Clinical Journal of the Internacional Institute for Bioenergetic Analysis. 2016;26:9-40.

35. Freire P. Pedagogia da autonomia: saberes necessários à prática educativa. Rio de Janeiro: Paz e Terra; 1996.

36. Agamben G. Nudez. Lisboa: Relógio D'Água; 2010.

37. Helfaer, PM. Fundamentos da análise energética. In: Clauer VH, organizadora. Múltiplos saberes em psicologia corporal. Recife: Libertas; 2015. p. 9-44. 